\title{
FEDERALISMO E POLÍTICAS SOCIAIS NO BRASIL problemas de coordenação e autonomia
}

\author{
Marta Arretche
}

\begin{abstract}
Resumo: Este texto pretende demonstrar que a concentração da autoridade política varia entre os Estados federativos e entre políticas particulares, condicionando a capacidade de coordenação governamental de políticas. Neste sentido, discute-se, no caso brasileiro, como se deu a adoção do governo federal. Palavras-chave: federalismo; coordenação governamental; políticas sociais.
\end{abstract}

Abstract: This study intends to show that the concentration of the political authority varies among the federative States and among the private politics, affecting the capacity of governmental coordination of politics. This way, it is argued, in the Brazilian case, how the adoption of the federal government was chosen. Key words: Federalism; governmental coordination; social politics.

$\mathrm{E}$

stados federativos são encarados como propensos a produzir níveis comparativamente mais baixos de gasto social (Petersen, 1995, Banting; Corbett, 2003), bem como menor abrangência e cobertura dos programas sociais (Weir; Orloff; Skocpol, 1988; Pierson, 1996). Tenderiam ainda a tornar mais difíceis os problemas de coordenação dos objetivos das políticas, gerando superposição de competências e competição entre os diferentes níveis de governo (Weaver; Rockman, 1993), dada a relação negativa entre dispersão da autoridade política e consistência interna das decisões coletivas. Adicionalmente, a existência de uma multiplicidade de pontos de veto no processo decisório implicaria que, em Estados federativos, as políticas nacionais tenderiam a se caracterizar por um mínimo denominador comum (Weaver; Rockman, 1993; Tsebelis, 1997).

Entretanto, a concentração da autoridade política varia entre os Estados federativos, dependendo do modo como estão estruturadas as relações entre Executivo e Legislativo no plano federal (Stepan, 1999), bem como da forma como estão distribuídas as atribuições de políticas entre os níveis de governo (Riker, 1964, 1975). Como conseqüência, pode-se esperar que estes tendam a apresentar variações em sua capacidade de coordenar políti- cas nacionais, dependendo da maneira como estão estruturadas estas relações em cada Estado.

Este trabalho pretende demonstrar que, adicionalmente, a concentração da autoridade política varia entre as políticas particulares, de acordo com as relações intergovernamentais em cada área específica de intervenção governamental. Para tanto, a distribuição federativa da autoridade política nas políticas sociais brasileiras será tomada como objeto de análise. Em conjunto, as instituições políticas nacionais tendem a dotar o governo federal de capacidade de coordenação das políticas sociais, a despeito das tendências centrífugas derivadas da descentralização fiscal e da fragmentação do sistema partidário.

$\mathrm{O}$ primeiro item deste artigo descreve muito brevemente os sistemas tributário e fiscal brasileiros, com o objetivo de demonstrar que a Constituição Federal de 1988 instituiu um sistema legal de repartição de receitas que limita a capacidade de gasto do governo federal e, por conseqüência, sua capacidade de coordenação de políticas. A sessão seguinte procura mostrar que as coalizões de governo aumentam a base vertical de apoio dos presidentes, mas não são suficientes para explicar a capacidade de coordenação federal das ações de governo. A terceira parte apresenta a distribuição intergovernamental de funções em 
algumas políticas sociais selecionadas, para destacar os recursos institucionais de que dispõe o governo federal para induzir as decisões dos governos subnacionais. $\mathrm{O}$ trabalho pretende demonstrar que, a despeito das tendências dispersivas derivadas tanto dos sistemas tributário e fiscal quanto do sistema partidário, o governo federal dispõe de instrumentos para coordenar as políticas sociais, ainda que estes variem entre as diferentes políticas.

\section{OS SISTEMAS FISCAL E TRIBUTÁRIO BRASILEIROS}

A federação brasileira adotou desde sua origem, na Constituição Federal de 1891, o regime de separação de fontes tributárias, discriminando impostos de competência exclusiva dos Estados e da União. ${ }^{1}$ A partir de então, a evolução histórica da estrutura tributária nacional, particularmente no que diz respeito à distribuição das competências exclusivas, caracterizou-se por mudanças lentas e graduais, sendo as maiores rupturas operadas pela centralização da Reforma Tributária do regime militar (1965-68) e, no período seguinte, a descentralização fiscal da Constituição de 1988 (Varsano, 1996; Affonso, 1999).

No sistema atual, a arrecadação tributária é bastante concentrada: os cinco principais impostos são responsáveis por mais de $70 \%$ da arrecadação total, sendo quatro deles arrecadados pela União. ${ }^{2} \mathrm{O}$ imposto mais importante é arrecadado pelos Estados: o Imposto sobre Circulação de Mercadorias e Serviços (ICMS) (Varsano et al., 1998). Na última década, a elevação da carga tributária - de $25 \%$ em 1991 para 34\% em 2001 (AFE/BNDES, 2002) - foi derivada principalmente do esforço tributário da União e, complementarmente, dos municípios (Prado, 2001). Em 2002, 70,1\% do total da arrecadação tributária foi realizado pela União, 25,5\% pelos Estados e 4,3\% pelos municípios (Gráfico 1).

A arrecadação de tributos é extremamente desigual no plano horizontal, isto é, entre os governos subnacionais. A razão entre os Estados com maior e menor capacidade de arrecadação tributária própria em 1997 foi de 9,4 (Prado, 2001:50). No interior de cada Estado, municípios de mesmo tamanho apresentam enorme diversidade de arrecadação. Excetuando-se as capitais - com arrecadação até dez vezes superior à dos demais municípios de seu próprio Estado -, os municípios de maior porte não revelam melhor desempenho do que os pequenos, independentemente do nível de renda do Estado em que estão localizados (Prado, 2001).
Desde a Constituição de 1946, esta desigualdade horizontal de capacidade de arrecadação tem sido compensada por um sistema de transferências fiscais. Transferências obrigatórias de caráter constitucional distribuem parte das receitas arrecadadas pela União para Estados

\section{GRÁFICO 1}

Participação dos Três Níveis de Governo na Arrecadação Tributária Brasil - 1960-2002

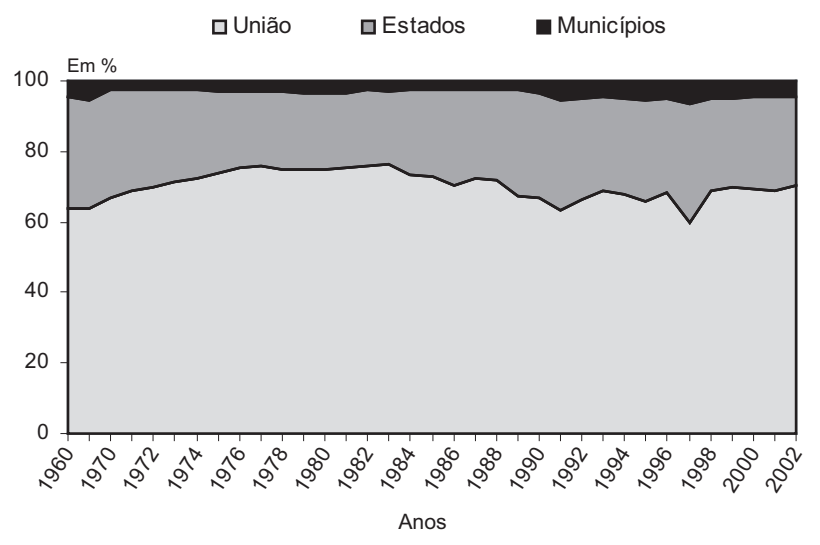

Fonte: Varsano et al. (1998); Prado (2001); AFE/BNDES (2002); SRF (2003).

e municípios, bem como dos Estados para seus respectivos municípios (Varsano, 1996). Assim, os convencionalmente chamados de ciclos de centralização (Reforma Tributária de 1965-68) e descentralização (Constituições Federais de 1946 e 1988) do sistema fiscal brasileiro não se referem a processos de mudança na distribuição da autoridade para tributar, mas estão diretamente associados às alíquotas aplicadas aos impostos de repartição obrigatória, bem como à autonomia de gasto dos governos locais sobre os recursos recebidos. Assim, em 1968, as transferências constitucionais da União somavam $10 \%$ da arrecadação de seus dois principais tributos e a quase totalidade destas transferências estava vinculada a itens predefinidos de gasto (Medeiros, 1986). Na Constituição de 1988, o Fundo de Participação dos Estados e o Fundo de Participação dos Municípios têm como fonte de receita a soma de $44 \%$ da receita dos dois maiores impostos federais, ${ }^{3}$ sendo que as receitas provenientes das transferências constitucionais podem ser gastas de modo bastante autônomo pelos governos subnacionais, excetuando-se as vinculações constitucionais de gasto em saúde e educação. 
No plano vertical, o atual sistema de transferências fiscais permite que quase todos os ganhos relativos sejam apropriados pelos municípios, uma vez que seus resultados são neutros para os Estados (Serra; Afonso, 1999). Em 2002, a receita disponível (arrecadação própria + transferências) da União foi de $60 \%$ do total das receitas, ao passo que os municípios se apropriaram de $15 \%$, permanecendo os Estados no mesmo patamar que estavam anteriormente à redistribuição (Gráfico 2). Além disso, este sistema favorece os municípios de pequeno porte. Gomes e MacDowell (1997) estimaram ser de $91 \%$ a participação das receitas de transferência nos municípios de menos de 5.000 habitantes. Em 22 Estados brasileiros, quanto menor a população do município, maior o seu ganho de receita derivado das transferências constitucionais, vale dizer, maior a disponibilidade de recursos per capita com liberdade alocativa, uma vez realizadas as transferências (Prado, 2001:68).

No plano horizontal, este sistema redistribui receita dos Estados mais desenvolvidos para os menos desenvolvidos (Rezende; Cunha, 2002). Entretanto, as regras que acabaram por reger as transferências constitucionais têm

\section{GRÁFICO 2}

Participação dos Três Níveis de Governo na Receita Disponível Brasil - 1960-2002

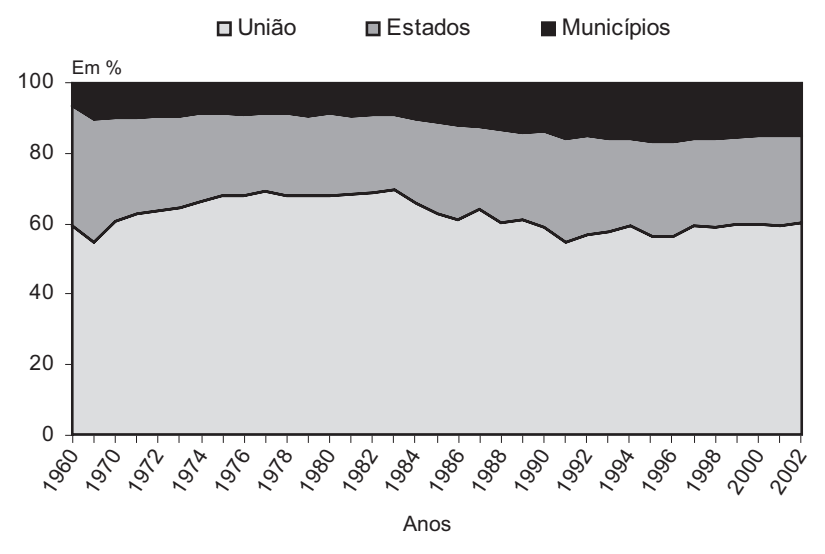

Fonte: Varsano et al. (1998); Prado (2001); AFE/BNDES (2002); SRF (2003).

por conseqüência recriar novas desigualdades entre as Unidades da Federação (Prado, 2001:54). É enorme a variação na receita disponível entre os municípios e Estados brasileiros. A razão entre a receita média per capita dos municípios com mais de um milhão de habitantes, na
Região Sudeste, e dos municípios com menos de 20 mil habitantes, nas Regiões Norte e Nordeste, pode ser de até 46 vezes (Gomes; MacDowell, 1997:11). Uma vez realizadas as transferências constitucionais, a receita disponível per capita do Estado de Roraima foi de duas vezes a de São Paulo, em 1997 (Prado, 2001:55).

Na prática, estas desigualdades limitam definitivamente a possibilidade de que se estabeleçam constitucionalmente competências exclusivas entre os níveis de governo para as ações sociais. Limitam também a possibilidade de arranjos federativos em que, ao conferir autonomia aos governos locais, deixassem basicamente aos eleitores a tarefa de elevar o gasto social dos governos locais.

O sistema brasileiro de repartição de receitas tributárias é essencialmente um sistema legal (Prado, 2001), pelo qual receitas tributárias sem vinculação de gasto - com exceção das obrigações constitucionais de gasto em saúde e educação - são garantidas aos governos subnacionais, notadamente aos municípios de pequeno porte. Combinado a compromissos financeiros acumulados no passado, direitos assegurados em lei e vinculações constitucionais do gasto federal, este sistema produz alta rigidez do orçamento federal (Rezende; Cunha, 2003) - isto é, reduzido espaço para introdução de novos itens de gasto -, de tal sorte que esta tem implicado necessariamente elevação da carga tributária.

Estados e municípios, por sua vez, contam com recursos garantidos, independentemente tanto de lealdade política ou adesão a políticas federais quanto de seu esforço tributário. Sistemas tributários e fiscais caracterizados por elevado nível de dependência de transferências fiscais e ausência de vínculo entre quem taxa e quem gasta tendem a produzir baixo compromisso com o equilíbrio fiscal por parte dos governos subnacionais (Rodden, 2001), tendência esta que no caso brasileiro foi limitada pela Lei de Responsabilidade Fiscal. Além disso, a autoridade do governo federal para induzir as decisões dos governos locais, no sentido de que estas venham a coincidir com as suas próprias prioridades, permanece limitada, uma vez que estes detêm autonomia fiscal e política, tendo, portanto, condições institucionais para não aderir às políticas federais.

Adicionalmente, como as transferências fiscais têm limitado efeito equalizador sobre as diferenças interestaduais e intermunicipais de capacidade de gasto, permanece necessária a ação do governo federal para viabilizar patamares básicos de produção de serviços sociais. 
Em suma, a coordenação federal dos programas sociais se justifica tanto por razões relacionadas à coordenação das decisões dos governos locais quanto para corrigir desigualdades de capacidade de gasto entre Estados e municípios.

\section{O GRAU DE DESCENTRALIZAÇÃO POLÍTICA DA FEDERAÇÃO}

A autonomia política e fiscal dos governos estaduais e municipais permite que estes adotem uma agenda própria, independente da agenda do Executivo federal. As relações verticais na federação brasileira - do governo federal com Estados e municípios e dos governos estaduais com seus respectivos municípios - são caracterizadas pela independência, pois Estados e municípios são entes federativos autônomos. Em tese, as garantias constitucionais do Estado federativo permitem que os governos locais estabeleçam sua própria agenda na área social.

Imaginemos um objetivo nacional de política social, tal como elevar os padrões de qualidade do ensino fundamental, em vista das novas demandas da sociedade do conhecimento vis-à-vis os baixos índices de desempenho escolar dos estudantes brasileiros. A realização deste objetivo suporia a mobilização dos governos estaduais e municipais, que são os gestores das redes de ensino. $\mathrm{O}$ reconhecimento generalizado de que esta deveria ser uma prioridade nacional não implica que estes viessem a estabelecer a elevação da qualidade do ensino como uma prioridade de política pública no plano local e nem que, mesmo que venham a fazê-lo, estejam de acordo com as estratégias mais adequadas para elevar a qualidade do ensino.

Foi este precisamente o resultado da vinculação de gasto em educação da Constituição Federal de 1988. Embora Estados e municípios cumprissem a regra constitucional de gastar $25 \%$ de suas receitas em ensino, cada um estabeleceu sua própria prioridade de gasto. Ainda que a autonomia de decisões de alocação de gasto tenha possivelmente produzido melhor adaptação a necessidades locais, seus efeitos foram a elevação generalizada do gasto acompanhada de superposição e a dispersão das ações.

Sob tais condições institucionais, os partidos políticos poderiam operar como um mecanismo de contrapeso às tendências centrífugas do federalismo. Esta possibilidade, contudo, depende do grau de centralização do sistema partidário (Riker, 1975). No caso brasileiro, a fragmentação do sistema partidário - que passou de bipartidário para altamente fragmentado a partir de 1988 (Nicolau, 1996) - tem implicado reduzido número de prefeitos e governadores do mesmo partido do presidente (Tabela 1). De 1990 até hoje, menos de 1/3 dos governadores era do mesmo partido do presidente. A única exceção foi o presidente Sarney, porque em seu mandato o sistema partidário contava com apenas três partidos efetivos, isto é, não era ainda multipartidário. Com exceção do presidente Itamar Franco, nenhum outro contou com mais de $18 \%$ dos prefeitos eleitos pelo seu próprio partido, ${ }^{4}$ ainda que todos tenham aumentado o número de prefeitos de seus respectivos partidos nas eleições realizadas durante seus mandatos. Portanto, mesmo na presença de partidos com estruturas decisórias centralizadas - uma outra dimensão do grau de centralização do sistema partidário -, a frágil base de apoio partidário dos presidentes na federação brasileira limitaria a capacidade dos partidos operarem como instâncias de coordenação das ações de governo.

A construção de coalizões de governo tende a reduzir estes efeitos (Tabela 1). No cenário menos favorável, montar coalizões de governo permitiu aos presidentes dobrar o percentual de prefeitos e governadores de sua base de apoio na estrutura vertical da federação. O presidente Fernando Henrique multiplicou por quatro o percentual de prefeitos da sua base de apoio em seu segundo mandato. A montagem de uma coalizão de governo permitiu que os presidentes Itamar Franco e Fernando Henrique contassem com bases de apoio vertical próximas ou superiores a 2/3 do total de governadores e prefeitos.

Se a estrutura de todos os partidos da coalizão fosse centralizada - isto é, se todos os prefeitos e governadores se subordinassem às direções de seus respectivos partidos -, a construção de coalizões de governo compensaria os efeitos centrífugos derivados da descentralização fiscal. Adicionalmente, o efeito-demonstração da adesão dos governos da base de apoio vertical às políticas do Executivo federal poderia ter um efeito de constrangimento sobre os governos dos partidos de oposição, fortalecendo assim a capacidade de coordenação do governo federal.

No Brasil, não existem pesquisas conclusivas que permitam afirmar com segurança qual é o efeito dos partidos sobre as relações verticais da federação. A literatura sustenta que um dos efeitos prováveis do federalismo é descentralizar a estrutura decisória dos partidos, ao permitir que o controle de postos no Executivo opere como um recurso de poder nas barganhas intra-partidárias (Riker, 1975). 
O exame da trajetória das políticas sociais brasileiras desde o governo Sarney revela que ocorreram variações na capacidade de coordenação federativa das políticas sociais entre os presidentes. Os governos Sarney, Collor e Itamar tiveram pouco sucesso em suas tentativas de reformas que envolveram a coordenação nacional destas políticas (Almeida, 1995; Affonso; Silva, 1996), ao passo que as duas gestões do governo Fernando Henrique foram mais bemsucedidas em sua capacidade de induzir as decisões dos governos locais (Arretche, 2002). Uma análise que simplesmente constatasse a coexistência no tempo de dois fenômenos permitiria afirmar que existe uma relação de causalidade entre a construção de bases verticais de apoio partidário na federação e a capacidade de coordenação das políticas nacionais. Observe-se, na Tabela 1, que as bases de apoio vertical do governo Fernando Henrique variaram entre $67 \%$ e $78 \%$ do total de governadores e prefeitos. Contudo, se tais bases de apoio fossem uma condição suficiente para a capacidade de coordenação federativa, tenderíamos a encontrar no governo do presidente Itamar Franco resultados mais positivos. ${ }^{5}$ Assim, a primeira parece ser uma condição de possibilidade para a segunda.

TABELA 1

Sustentação Partidária do Executivo Federal na Federação Brasil - 1985-2004

\begin{tabular}{|c|c|c|c|c|c|c|}
\hline $\begin{array}{l}\text { Governadores e } \\
\text { Prefeitos }\end{array}$ & $\begin{array}{c}\text { Sarney } \\
\text { (PMDB-PFL) }\end{array}$ & $\begin{array}{c}\text { Collor } \\
\text { (PRN-PDS- } \\
\text { PFL-PTB) }\end{array}$ & $\begin{array}{c}\text { Itamar } \\
\text { (PMDB-PFL-PTB- } \\
\text { PSDB-PSB)(1) }\end{array}$ & $\begin{array}{c}\text { FHC } 1 \\
\text { (PSDB-PFL-PTB- } \\
\text { PMDB) }\end{array}$ & $\begin{array}{c}\text { FHC } 2 \\
\text { (PSDB-PFL-PTB- } \\
\text { PMDB-PPB) }\end{array}$ & $\begin{array}{c}\text { Lula } \\
\text { (PT-PL-PSB- } \\
\text { PTB-PPS-PDT- } \\
\text { PCdoB-PMDB)(2) }\end{array}$ \\
\hline Total de Governadores & (3) $22 / 23$ & 27 & 27 & 27 & 27 & 27 \\
\hline Total de Prefeitos & $\begin{array}{r}\text { (4) } 3.941 / 4.142 \\
\text { (5) } 4.287\end{array}$ & $\begin{array}{l}\text { (5) } 4.287 \\
\text { (6) } 4.762\end{array}$ & 4.762 & $\begin{array}{l}\text { (6) } 4.762 \\
\text { (7) } 5.378\end{array}$ & $\begin{array}{l}\text { (7) } 5.378 \\
\text { (8) } 5.559\end{array}$ & 5.559 \\
\hline \multicolumn{7}{|c|}{ Governadores do Partido do Presidente } \\
\hline Números Absolutos & (3) $9 / 22$ & 0 & 8 & 6 & 7 & 3 \\
\hline Em porcentagem & (3) $41,0 / 96,0$ & 0 & 30,0 & 22,0 & 26,0 & 11,0 \\
\hline \multicolumn{7}{|c|}{ Governadores na Coalizão de Governo } \\
\hline Números Absolutos & (3) $9 / 23$ & 11 & 18 & 18 & 21 & (9) $10 / 14$ \\
\hline Em porcentagem & (3) $41,0 / 100,0$ & 41,0 & 67,0 & 67,0 & 78,0 & (9) $37,0 / 52,0$ \\
\hline \multicolumn{7}{|c|}{ Prefeitos do Partido do Presidente } \\
\hline Números Absolutos & (4) $\begin{array}{r}1.377 / 1.504 \\
\text { (5) } 1.606\end{array}$ & $\begin{array}{r}\text { (5) } 3 \\
\text { (6) } 98\end{array}$ & (6) 1.605 & $\begin{array}{l}\text { (6) } 317 \\
\text { (7) } 921\end{array}$ & $\begin{array}{l}\text { (7) } 921 \\
\text { (8) } 990\end{array}$ & 187 \\
\hline Em porcentagem & $\begin{array}{r}\text { (4) } 35,0 / 36,0 \\
\text { (5) } 37,0\end{array}$ & $\begin{array}{l}\text { (5) } 0,1 \\
\text { (6) } 2,1\end{array}$ & 34,0 & $\begin{array}{l}\text { (6) } 6,6 \\
\text { (7) } 17,0\end{array}$ & $\begin{array}{l}\text { (7) } 17,0 \\
\text { (8) } 18,0\end{array}$ & 3,0 \\
\hline \multicolumn{7}{|c|}{ Prefeitos na Coalizão de Governo } \\
\hline Números Absolutos & (4) $\begin{array}{r}1.377 / 1.529 \\
2.664\end{array}$ & $\begin{array}{l}\text { (5) } 1.839 \\
\text { (6) } 1.894\end{array}$ & 3.238 & $\begin{array}{l}\text { (6) } 3.190 \\
\text { (7) } 4.157\end{array}$ & $\begin{array}{l}\text { (7) } 4.157 \\
\text { (8) } 4.291\end{array}$ & (9) $1.407 / 2.376$ \\
\hline Em porcentagem & $\begin{array}{r}\text { (4) } 35,0 / 37,0 \\
(5) 62,0\end{array}$ & $\begin{array}{l}\text { (5) } 43,0 \\
\text { (6) } 40,0\end{array}$ & 68,0 & $\begin{array}{r}\text { (6) } 67,0 \\
77,0\end{array}$ & $\begin{array}{l}\text { (7) } 67,0 \\
\text { (8) } 77,0\end{array}$ & (9) $25,0 / 43,0$ \\
\hline
\end{tabular}

Fonte: Adaptado de Roma; Braga (2002); Figueiredo; Limongi (1999), com base no Banco de Dados Eleitorais do Brasil, luperj.

(1) Desconsidera o fato de que o PSB saiu da coalizão e o PP entrou na coalizão em 1993. O PP não contava com nenhum governador ou prefeito no período. O PSB elegeu 48 prefeitos nas eleições de 1992.

(2) Em 2004, o PDT saiu e o PMDB entrou para a coalizão.

(3) Antes e depois das eleições de 1986.

(4) Antes e depois das eleições de 1985. Nas eleições de 1985, foram eleitos mais 127 prefeitos pelo PMDB, em 201 municípios.

(5) Resultados eleitorais de 1988.

(6) Resultados eleitorais de 1992. O PL entrou para a coalizão de sustentação do governo Itamar em 1991.

(7) Resultados eleitorais de 1996. No governo FHC1, os dados sobre os prefeitos da coalizão de governo incluem o PPB.

(8) Resultados eleitorais de 2000.

(9) Antes e depois da saída do PDT e da entrada do PMDB na coalizão de governo (2003/2004). 
$\mathrm{Na}$ verdade, o exame dos mecanismos e processos que tornam possível coordenar ações entre esferas de governo indica que esta capacidade é diretamente afetada pelo modo como estão estruturadas as relações federativas nas políticas particulares. Pesquisas sobre as políticas implementadas pelos governos locais não concluíram que exista relação significativa entre as decisões de governo e o pertencimento às siglas partidárias nacionais (Rodrigues, 2003; Marques; Arretche, 2003). Além disso, se a adesão aos programas federais dependesse essencialmente da construção de bases verticais de apoio na federação, a tendência seria encontrar variações significativas entre os diferentes presidentes no que diz respeito à capacidade de coordenação de todas as políticas, bem como pequenas variações nesta capacidade em um mesmo mandato presidencial. Na verdade, não é este o caso. A forma como estão estruturadas as relações federativas nas políticas específicas afeta as estratégias possíveis para coordenação vertical das políticas nacionais.

\section{POLÍTICAS SOCIAIS E RELAÇÕES INTERGOVERNAMENTAIS}

Os constituintes de 1988 optaram pelo formato das competências concorrentes para a maior parte das políticas sociais brasileiras. Na verdade, as propostas para combinar descentralização fiscal com descentralização de competências foram estrategicamente derrotadas na ANC 198788 (Souza, 1997). Assim, qualquer ente federativo estava constitucionalmente autorizado a implementar programas nas áreas de saúde, educação, assistência social, habitação e saneamento. Simetricamente, nenhum ente federativo estava constitucionalmente obrigado a implementar programas nestas áreas. Decorre deste fato a avaliação de que a Constituição de 1988 descentralizou receita, mas não encargos (Almeida, 1995; Affonso; Silva, 1996; Affonso, 1999; Willis et al., 1999). Esta distribuição de competências é propícia para produzir os efeitos esperados pela literatura sobre federalismo e políticas públicas: superposição de ações; desigualdades territoriais na provisão de serviços; e mínimos denominadores comuns nas políticas nacionais. Estes efeitos, por sua vez, são derivados dos limites à coordenação nacional das políticas.

Ocorre que a Constituição Federal de 1988 não alterou a estrutura institucional de gestão das políticas sociais herdada do regime militar. Mesmo as medidas de reforma aprovadas e implementadas pelos sucessivos presidentes - posteriormente à Constituição Federal de 1988 - pouco ou nada alteraram esta estrutura prévia, que é centralizada para as políticas de saúde e desenvolvimento urbano e descentralizada para a política de educação fundamental. No início dos anos 90, a distribuição federativa dos encargos na área social derivava menos de obrigações constitucionais e mais da forma como historicamente estes serviços estiveram organizados em cada política particular. A capacidade de coordenação das políticas setoriais dependeu em grande parte destes arranjos institucionais herdados.

\section{Política de Saúde}

Na distribuição intergovernamental de funções, a União está encarregada do financiamento e formulação da política nacional de saúde, bem como da coordenação das ações intergovernamentais. Isto significa que o governo federal - isto é, o Ministério da Saúde - tem autoridade para tomar as decisões mais importantes nesta política setorial. Neste caso, as políticas implementadas pelos governos locais são fortemente dependentes das transferências federais e das regras definidas pelo Ministério da Saúde. Em outras palavras, o governo federal dispõe de recursos institucionais para influenciar as escolhas dos governos locais, afetando sua agenda de governo.

A edição de portarias ministeriais tem sido o principal instrumento de coordenação das ações nacionais em saúde. Isto quer dizer que a principal arena de formulação da política nacional tem sido o próprio poder Executivo e, marginalmente, o Congresso Nacional. O conteúdo destas portarias consiste, em grande medida, em condicionar as transferências federais à adesão de Estados e municípios aos objetivos da política federal. Nas condições em que se reduza a incerteza quanto ao fluxo das transferências, tornando crível que estas serão efetivamente realizadas, aumenta exponencialmente a capacidade federal de coordenar as ações dos governos estaduais e municipais.

É esta estrutura institucional que explica que, ao longo dos anos 90, o Ministério da Saúde tenha conquistado a adesão dos governos estaduais e municipais ao SUS. Em maio de 2002, 5.537 dos 5.560 municípios brasileiros $99,6 \%$ do total - haviam assumido a gestão parcial ou integral dos serviços de saúde. Em 2000, os municípios brasileiros foram responsáveis, em média, por $89 \%$ do total da produção ambulatorial no Brasil, com um desvio padrão de $19 \%$ (consideradas todas as categorias de provedores), e por $84 \%$ da rede ambulatorial, média esta acompanhada de desvio padrão decrescente. Isto é, a rede e a 
produção de serviços ambulatoriais se tornaram basicamente municipais, o que não era absolutamente a realidade da distribuição destes serviços no início dos anos 90 (Marques; Arretche, 2003).

Estes resultados são, em boa medida, explicados pela capacidade de o Ministério da Saúde induzir as decisões dos governos municipais. Estes eram responsáveis por 9,6\% do total do gasto consolidado em saúde em 1985, por 35\% em 1996 (Medici, 2002) e por 43\% em 2000 (Ferreira, 2002). Pelo conceito de origem dos recursos, a participação dos municípios passou de 9,3\% em 1985 para 28\% em 1996 (Medici, 2002).

A participação de Estados e municípios no processo de formulação da política de saúde, por sua vez, está institucionalizada por meio de conselhos com representação de Estados e municípios. ${ }^{6}$ A institucionalização destes espaços de negociação suprimiu do Ministério da Saúde a possibilidade de estabelecer unilateralmente as regras de funcionamento do SUS. Tais conselhos funcionam como um mecanismo de contrapeso à concentração de autoridade conferida ao Executivo federal.

\section{Políticas de Habitação e Saneamento}

O sistema nacional de oferta de serviços de habitação e saneamento foi instituído nos anos 60 e 70. As reformas institucionais realizadas nas décadas de 80 e 90 não modificaram a estrutura básica da distribuição federativa de funções. O governo federal arrecada e redistribui, por meio de empréstimos, os recursos da principal fonte de financiamento destas políticas: um fundo destinado a indenizar trabalhadores demitidos sem motivo, cuja arrecadação líquida é direcionada ao financiamento de programas de saneamento e habitação (o Fundo de Garantia por Tempo de Serviço - FGTS).

Os serviços de saneamento básico são providos por 27 companhias estaduais, que controlam a maior parte das operações no setor, com base em contratos de concessão dos serviços com mais de 4.000 municípios brasileiros. Nos demais municípios, os serviços são operados por autarquias e órgãos municipais. A produção de habitações para população de baixa renda é realizada por companhias municipais, com atuação de âmbito regional. ${ }^{7}$ Diante do expressivo volume de recursos necessários à produção de serviços de infra-estrutura urbana e de moradia, é reduzido o número de Estados e municípios brasileiros capazes de implementar políticas efetivas de habitação e saneamento sem aportes federais. O papel do governo federal como financiador lhe confere recursos institucionais para coordenar as escolhas dos governos locais.

A distribuição da autoridade decisória nesta política particular confere às comissões estaduais, nomeadas pelos governadores, a autoridade para distribuir os financiamentos no interior de cada Estado. Entretanto, o conselho gestor do FGTS define as regras de operação dos programas, assim como o agente financeiro do Fundo - a CEF - detém o poder para autorização definitiva. Nem o Conselho Curador do FGTS nem a CEF contam com representação federativa em suas principais instâncias decisórias. São órgãos com controle majoritário do governo federal. A ausência de uma representação institucionalizada dos governos subnacionais nas arenas decisórias federais permite ao governo federal razoável autonomia para definir unilateralmente as regras de distribuição dos empréstimos federais.

Tal como na área de saúde, portanto, a União está encarregada das funções de financiamento e formulação da política nacional. Entretanto, nesta política particular, a autoridade é ainda mais concentrada do que na área da saúde, em vista da ausência de representação federativa nas principais arenas decisórias.

\section{Política de Educação Fundamental}

A oferta de ensino fundamental é responsabilidade de Estados e municípios, sendo que estas duas redes operam de modo inteiramente independente. Devido à forma como historicamente evoluiu a expansão das matrículas, é muito variável a participação das duas redes na oferta de matrículas em cada Estado: em 1996, no Estado de São Paulo, $87,5 \%$ das matrículas eram oferecidas pelo governo estadual, ao passo que em Alagoas e no Maranhão eram os municípios que detinham $65 \%$ das matrículas (Vazquez, 2003:37).

As desigualdades horizontal e vertical de capacidade de gasto da federação brasileira implicam diferenças na carreira e nos salários dos professores, na natureza e qualidade dos serviços educacionais, bem como no nível de gasto/aluno. Em 1996, os municípios do Estado do Maranhão gastavam em média R\$ 100 ao ano com seus alunos, ao passo que o governo do Estado gastava $\mathrm{R} \$ 385$. Em São Paulo, por sua vez, este gasto era de R\$1.039 para os municípios e de $\mathrm{R} \$ 569$ para o governo estadual (Vazquez, 2003:39).

A Constituição Federal de 1988 definiu como concorrentes as competências na educação fundamental, estabelecendo apenas que esta deveria ser oferecida preferen- 
cialmente pelos governos municipais. Além disso, obriga governos estaduais e municipais a gastarem $25 \%$ de sua receita disponível em ensino. Neste caso, diferentemente da política de saúde, o governo federal não é o principal financiador, desempenhando uma função apenas supletiva, de financiar programas de alimentação dos estudantes das escolas públicas e de construção e capacitação das unidades escolares, contando, portanto, com recursos institucionais bem mais limitados para coordenar a adoção de objetivos nacionais de política.

É por esta razão que, para alcançar um objetivo nacional - por exemplo, reduzir as assimetrias intra-estaduais de gasto no ensino fundamental e promover a valorização salarial dos professores -, o governo Fernando Henrique adotou como estratégia a aprovação de uma emenda constitucional, como o Fundef. ${ }^{8}$

Na prática, a implementação desta Emenda Constitucional implicou uma minirreforma tributária de âmbito estadual, à medida que, a cada ano, $15 \%$ das receitas de Estados e municípios são automaticamente retidas e contabilizadas em um Fundo Estadual - o Fundef. Suas receitas são redistribuídas, no interior de cada Estado, entre governos estaduais e municipais de acordo com o número de matrículas oferecidas anualmente. O Fundef estabeleceu assim um vínculo entre encargos e receitas fiscais, além de garantir a efetiva transferência dos recursos (Oliveira, 2001), cujo efeito foi eliminar as desigualdades intra-estaduais de gasto no ensino fundamental (Vazquez, 2003). ${ }^{9}$

Neste caso, para alcançar seus objetivos, o governo federal adotou a estratégia de constitucionalizar as transferências intra-estaduais, eliminando a incerteza quanto ao recebimento dos recursos vinculados à oferta de matrículas. Para obter o comportamento desejado por parte dos governos locais, criou uma obrigação constitucional, dada sua limitada capacidade institucional de afetar as escolhas dos governos locais.

\section{COMO ESTÃO COMBINADAS NO BRASIL AS DIMENSÕES DE COORDENAÇÃO E AUTONOMIA?}

Com exceção da política de educação fundamental, a concentração de autoridade no governo federal caracteriza as relações federativas na gestão das políticas, pois à União cabe o papel de principal financiador, bem como de normatização e coordenação das relações intergovernamentais.

O formato de gestão que concentra autoridade no governo federal apresenta vantagens para a coordenação dos objetivos das políticas no território nacional, pois permite reduzir o risco de que os diferentes níveis de governo imponham conflitos entre programas e elevação dos custos da implementação, cuja ocorrência é mais provável em Estados Federativos (Weaver; Rockman, 1993). Além disso, a concentração do financiamento no governo federal permitiria alcançar resultados redistributivos (Banting; Corbett, 2003), reduzindo desigualdades horizontais de capacidade de gasto.

A descentralização de encargos na política de saúde foi derivada do uso da autoridade financiadora e normatizadora do governo federal para obter adesão dos municípios a um dado objetivo de política. Condicionar - e garantir a efetividade das - transferências à adesão dos governos locais à agenda do governo federal revelou-se uma estratégia de forte poder de indução sobre as escolhas dos primeiros. Reduzida a incerteza sobre a regularidade na obtenção de recursos, aumentou a disposição para assumir a responsabilidade pela provisão de serviços de saúde.

A agenda de privatizações das empresas estaduais de saneamento no passado recente também foi condicionada pela capacidade de indução do governo federal, derivada de sua autoridade sobre a principal fonte de financiamento. Neste caso, ao controle sobre o financiamento acrescenta-se a inexistência de representação federativa nas instâncias decisórias federais. Esta combinação permitiu à União definir unilateralmente as regras para obtenção de empréstimos, endurecendo as condições para sua concessão e, portanto, desfinanciando os governos subnacionais nesta área de política.

Nas áreas de política em que o governo federal não dispõe de recursos institucionais para alterar as escolhas dos governos locais, a estratégia de constitucionalizar encargos revelou-se bem-sucedida. Tratou-se de aprovar emendas à Constituição que reduzem muito a margem de escolhas dos governos subnacionais, obrigando-os a adotar o comportamento considerado desejável pelo governo federal. Esta foi a estratégia adotada para equalizar os níveis intra-estaduais de gasto em ensino fundamental e elevar os salários dos professores. Na área da saúde, esta foi a estratégia adotada para vincular receitas a níveis de gasto em saúde. ${ }^{10}$

Na verdade, a aprovação de emendas à Constituição é relativamente mais fácil no Brasil do que em outras federações. A maioria de 2/3 em duas sessões legislativas em cada Câmara (dos Deputados e Senado) é o requisito essencial para sua aprovação. Não é necessária a aprovação nas 
casas legislativas estaduais, como nos Estados Unidos, por exemplo, mesmo que a matéria afete os interesses dos governos subnacionais. Nos casos acima mencionados, a obtenção do apoio do presidente para a iniciativa legislativa, que permitiu mobilizar favoravelmente a coalizão de sustentação do governo no Congresso, foi o fator central para o sucesso do Executivo na arena parlamentar.

A constitucionalização de encargos ou níveis de gasto é, entretanto, uma estratégia que encontra limites nas desigualdades horizontais da federação brasileira. A desigualdade horizontal dos governos subnacionais permanece recomendando cautela na definição constitucional de competências exclusivas na gestão das políticas sociais, ainda que a descentralização fiscal e de políticas tenha aumentado as capacidades estatais - administrativas, fiscalizadoras e de produção de serviços - dos governos subnacionais. A vinculação de gasto tende ainda a reproduzir no plano da implementação das políticas desigualdades preexistentes de capacidade de gasto.

Os resultados redistributivos da concentração de autoridade no governo federal não se revelaram entretanto tão evidentes. A municipalização dos serviços de saúde não foi acompanhada de redução na desigualdade intermunicipal nos padrões de sua oferta (Marques; Arretche, 2003). A complementação da União para o ensino fundamental teve resultados quase nulos sobre as desigualdades interestaduais de padrões de gasto (Vazquez, 2003). Isto ocorre em parte porque estes desembolsos federais apresentam reduzido efeito redistributivo (Prado, 2001), mas também porque o objetivo de alcançar a descentralização teve mais centralidade do que os objetivos redistributivos nas estratégias adotadas nos anos 90. No entanto, a estrutura institucional para coordenação das políticas nacionais pode ser utilizada para obter as metas desejáveis.

\section{NOTAS}

Este texto é uma versão revista do trabalho "Federalismo, Relações Intergovernamentais e Políticas Sociais no Brasil", apresentado no Seminário Internacional "Análise Comparativa sobre Mecanismos de Gestão Inter-governamental e Formatação de Alternativas para o Caso Brasileiro", organizado pela Subchefia de Assuntos Federativos da Casa Civil da Presidência da República e o Fórum das Federações, em Brasília, 17 e 18 de setembro de 2003.

1. Os municípios só passaram a ter competência exclusiva para decretar tributos a partir da Constituição de 1934.

2. A saber, a contribuição para a previdência social, o Imposto de Renda (IR), a Contribuição para o Financiamento da Seguridade Social (Cofins) e o Imposto sobre Produtos Industrializados (IPI).
3. A Reforma Tributária de 1965-68 criou o Fundo de Participação dos Estados (FPE) e o Fundo de Participação dos Municípios (FPM), compostos de um percentual sobre a arrecadação federal do Imposto de Renda e do Imposto sobre Produtos Industrializados. Estes percentuais eram de 5\% para cada Fundo em 1968 e passaram a 21,5\% e $22,5 \%$, respectivamente, com a Constituição de 1988. Os Fundos de Participação movimentam cerca de $20 \%$ do total da receita administrada pela União (Prado, 2001:54).

4. A tabela considera os partidos pelos quais os governadores e prefeitos foram eleitos, ignorando possíveis trocas de partidos durante o mandato. Esta decisão tende a subestimar o número de prefeitos da base de apoio do presidente. Para os governadores, tende a refletir a realidade, pois o fenômeno de troca de partidos entre governadores é pouco comum. Agradecimentos a Maria do Socorro Braga por esta informação.

5. A comparação entre o desempenho dos dois governos é certamente afetada pelo fator "tempo de mandato", que não está sendo analisado aqui.

6. A NOB 93 institucionalizou a Comissão Intergestores Tripartite e as Comissões Intergestores Bipartite que, juntamente com o Conselho Nacional de Saúde, são fóruns de pactuação da política nacional de saúde.

7. Entre 1995 e 2000, 12 das 44 companhias habitacionais municipais fecharam devido à política de não financiamento do governo Fernando Henrique (Arretche, 2002).

8. A Emenda Constitucional do Fundef - EC 14/96 - estabelece que, pelo prazo de dez anos, Estados e municípios devem aplicar, no mínimo, $15 \%$ de todas as suas receitas exclusivamente no ensino fundamental. Além disso, $60 \%$ destes recursos devem ser aplicados exclusivamente no pagamento de professores em efetivo exercício do magistério. Para reduzir a desigualdade de gasto, a EC 14/96 estabelece que o governo federal deve complementar o gasto naqueles Estados em que um valor mínimo nacional não seja alcançado com base nas receitas dos governos locais.

9. Seus efeitos sobre as desigualdades de gasto entre os Estados foram quase nulos, particularmente devido aos reduzidos aportes de recursos da União (Vazquez, 2003).

10. A EC 29/2000 estabelece que até 2005 os Estados devem gastar no mínimo $12 \%$ de suas receitas em saúde. Para os municípios, esta vinculação deverá atingir o patamar de $15 \%$ das receitas e, para a União, a elevação do gasto em saúde deve acompanhar a variação do crescimento do PIB.

\section{REFERÊNCIAS BIBLIOGRÁFICAS}

AFE/BNDES. Informe-se, n.40, 2002.

AFFONSO, R. A Federação na encruzilhada. Revista Rumos. Os caminhos do Brasil em debate, v.1, n.2, p.29-38, 1999. (Publicação da Comissão Nacional para as comemorações do V centenário do descobrimento do Brasil).

AFFONSO, R.; SILVA, P.L.B. Descentralização e políticas sociais. São Paulo: Fundap, 1996.

ALMEIDA, M.H.T. de Federalismo e políticas sociais. Revista Brasileira de Ciências Sociais, v.28, n.10, p.88-108, 1995.

ARRETCHE, M. Federalismo e relações intergovernamentais no Brasil: a reforma dos programas sociais. Dados, v.45, n.3, p.431-57, 2002.

BANTING, K.; CORBETT, S. Federalismo y politicas de atención a la salud. In: Fórum das Federações/Institucional Nacional para el 
Federalismo y el Desarrollo Municipal. Federalismo y Políticas de Salud. Descentralización y relaciones intergubernamentales desde una perspectiva comparada. Ontário/México, 2003.

FERREIRA, S. Federalismo fiscal, municípios: despesa com saúde e transferências federais. Informe-se, Banco Federativo do BNDES, n.38, 2002.

FIGUEIREDO, A.; LIMONGI, F. Executivo e Legislativo na nova or dem constitucional. Rio de Janeiro: FGV, 1999.

GOMES, G.M.; MACDOWELL, C. Os elos frágeis da descentralização: observação sobre as finanças dos municípios brasileiros. In: Seminário Internacional sobre Federalismo e Governos Locais. La Plata, Argentina, 1997.

LAVINAS, L. Renda mínima: práticas e viabilidade. Novos Estudos Cebrap, n.53, p.65-84, 1999.

LAVINAS, L.; BARBOSA, M.L. de O. Combater a pobreza estimulando a freqüência escolar: o estudo de caso do Programa BolsaEscola de Recife. Dados, v.43, n.3, p.447-477, 2000

MARQUES, E.; ARRETCHE, M. Condicionantes locais da descentralização da política de saúde. Caderno CRH, n.39, 2003.

MEDEIROS, A.C. de. Politics and intergovernmental relations in Brazil: 1964-82. New York/London: Garland Publishing Inc., 1986.

MEDICI, A. El desafío de la descentralización: financiamiento público de la salud en Brasil. Washington, BID, 2002.

NICOLAU, J.M. Multipartidarismo e democracia: um estudo sobre o sistema partidário brasileiro (1985-94). Rio de Janeiro: FGV, 1996.

OLIVEIRA, F.A. Fundef e saúde: duas experiências (virtuosas?) de descentralização. Projeto Descentralização Fiscal e Cooperação Financeira Intergovernamental. Ebap/Fundação Konrad Adenauer, 2001. (Relatório de Pesquisa).

PETERSON, P. The price of federalism. New York, The Twentieth Century Fund, 1995.

PIERSON, P. The new politics of the Welfare State. World Politics, v.48, n.2, p.143-179, 1996.

PIOLA, S.; BIASOTO Jr., J. Financiamento do SUS nos anos 90. In: NEGRI, B.; GIOVANNI, G. Radiografia da saúde. Campinas: Instituto de Economia, 2001. p.219-232.

PRADO, S. Transferências fiscais e financiamento municipal no Brasil. Projeto Descentralização Fiscal e Cooperação Financeira Intergovernamental. Ebap/Fundação Konrad Adenauer, 2001. (Relatório de Pesquisa).

REZENDE, F.; CUNHA, A. (Coord.). O orçamento público e a transição do poder. Rio de Janeiro: FGV, 2003.

Contribuintes e cidadãos. Compreendendo o orçamento federal. Rio de Janeiro: FGV, 2002.

RIKER, W. Federalism. In: GREENSTEIN, F.; POLSBY, N. (Ed.). Handbook of political science. Massachussets, Addisón-Wesley Publishing Company, v.5, 1975.
Federalism, origin, operation, significance. Little, Brown and Company, 1964.

RODDEN, J. The dilemma of fiscal federalism: hard and soft budget constraints around the world. 2001. Mimeographed.

RODRIGUES, G. A ação político-partidária nas administrações municipais e seus reflexos sobre os gastos públicos em Santa Catarina. In: XXVII Encontro Nacional da ANPOCS. Caxambu, 2003.

ROMA, C.; BRAGA, M.S. Sistema partidário, eleições e a questão federativa no Brasil (1986-2000). In: PINTO, C.J.R.; SANTOS, A.M. (Org.). Partidos no Cone Sul. Rio de Janeiro: Fundação Konrad-Adenauer, 2002.

SERRA, J.; AFFONSO, J.R.R. Federalismo fiscal à brasileira: algumas reflexões. Revista do BNDES, v.6, n.12, p.3-30, 1999.

SOUZA, C. Constitutional engineering in Brazil. Houndmills/New York: Macmillan Press/St. Martins's Press, 1997.

SRF. Secretaria da Receita Federal. Carga Tributária no Brasil- 2002. Brasília, DF: Coordenação-Geral de Política Tributária, abr. 2003. (Estudos Tributários, n.11). Disponível em:

<http://www.receita.fazenda.gov.br/Publico/EstudoTributario/carga fiscal/CTB2002.pdf>. Acesso em: set. 2004.

STEPAN, A. Para uma nova análise comparativa do federalismo e da democracia: federações que restringem ou ampliam o poder da demos. Dados, v.42, n.2, p.197-251, 1999.

TSEBELIS, G. Processo decisório em sistemas políticos: veto players no presidencialismo, parlamentarismo, multicameralismo e multipartidarismo. Revista Brasileira de Ciências Sociais, v.12, n.34, p.89-118, 1997.

VARSANO, R. A evolução do sistema tributário brasileiro ao longo do século: anotações e reflexões para futuras reformas. Brasília: Ipea, 1996. (Texto para Discussão, n. 405).

VARSANO, R. et al. Uma análise da carga tributária no Brasil. Brasília: Ipea, 1998. (Textos para Discussão, n. 583).

VAZQUEZ, D.A. Educação, descentralização e desequilíbrios regionais: os impactos do Fundef. Dissertação (Mestrado) - Instituto de Economia da Unicamp, Campinas, 2003.

WEAVER, K.R.; ROCKMAN, B. Do institutions matter? Washington: Brookings Institutions, 1993.

WEIR, M.; ORLOFF, A.S.; SKOCPOL, T. The politics of social policy in the United States. Princeton, Princeton University, 1988.

WILLIS, E.; GARMAN, C. da C.B; HAGGARD, S. The politics of decentralization in Latin América. Latin American Research Review, v.34, n.1, p.7-56, 1999.

Marta Arretche: Professora do Departamento de Ciência Política da USP. Autora do livro Estado Federativo e Políticas Sociais (arretche@uol.com.br). 